\title{
Technical note: A portable on-chip assay system for absorbance and plasmonic detection of protein hormone in milk
}

\author{
Jayan Ozhikandathil, Simona Badilescu, and Muthukumaran Packirisamy ${ }^{1}$ \\ Optical-Bio Microsystems Laboratory, Department of Mechanical and Industrial Engineering, Concordia University, Montreal, Quebec, \\ Canada H3G 1M8
}

\begin{abstract}
This paper reports a portable device and method to extract and detect protein hormone in milk samples. Recombinant protein hormone spiked into milk samples was extracted by solid-phase extraction, and detection was carried out using the plasmonic property of gold nanoislands deposited on a glass substrate. Trace levels of hormone spiked in milk were analyzed by their optical absorbance property using a microfluidic chip. We built a portable assay system using disposable lab-on-chip devices. The proposed method is able to detect spiked recombinant protein hormone in milk at concentrations as low as $5 \mathrm{ng} / \mathrm{mL}$.
\end{abstract}

Key words: hormone, lab-on-chip, plasmonic detection, milk

\section{Technical Note}

Typically, a 100-g sample of cow milk contains water $(85.4 \mathrm{~g})$, proteins $(3.1 \mathrm{~g})$, fat $(3.5 \mathrm{~g})$, sugar $(4.4 \mathrm{~g})$, cholesterol (10 mg), calcium (100 mg), SFA (2.3 g), MUFA (0.8 g), and PUFA (0.1 g) (Hadjipanayiotou, 1995). Milk contains a large variety of proteins; the majority are caseins and the remainder are arrays of enzymes, proteins responsible for transporting nutrients, proteins responsible for resisting diseases (antibodies), and other proteins including naturally occurring protein hormones. This paper focused on developing a less-expensive and rapid detection device for protein hormone in milk and verifying its performance with spiked milk.

Most of the reported methods for measuring hormone in milk (Jindal and Ludri, 1990; Rochut et al., 2000; Castigliego et al., 2007; Heutmekers et al., 2007; Le Breton et al., 2010) are expensive and involve complex analytical processes. They are laboratory based, not portable, labor intensive, and time consuming. Hence, bioassays using lab-on-a-chip (LOC) devices are at-

Received October 4, 2014.

Accepted October 29, 2014

${ }^{1}$ Corresponding author: pmuthu@alcor.concordia.ca tractive because of several inherent advantages; they have high sensitivity, are low cost, and require only minute amounts of samples and reagents. We have recently reported on the labeled and label-free detection of bST (Ozhikandathil et al., 2012b; Ozhikandathil and Packirisamy, 2012b) and rbST (Ozhikandathil et al., 2012a; Ozhikandathil and Packirisamy, 2013) using optical LOC devices. However, due to the complexity of the experimental setup, the LOC were not portable. In addition, in our previous work, the detection experiments were not carried out in milk samples. The present work proposes a method of extraction of recombinant protein hormone from spiked milk and detection using a portable device.

The separation of proteins is an essential process in the detection of hormone in milk. A large variety of separation processes can be used; however, solid-phase extraction (SPE) is the most powerful method because it is faster and more accurate than other methods. Traditionally, SPE systems were used with chromatographic systems for the quantitative and qualitative analysis of bio-molecules. In this work, we report an SPE protocol for the separation of proteins from milk, combined with specific detection of hormone using gold nanoislands in a portable device. In our previous work, a simple and low-cost approach was reported for the deposition of gold nanoislands on glass substrate for plasmonic detection. However, that method was not investigated for the detection of hormone directly in milk samples.

This work reports a low-cost and simple procedure to detect hormone in milk samples using a portable device and a microfluidics chip. The proposed portable optical device is capable of measuring the absorbance of biological species and nanostructures for screening antigen-antibody interactions using microfluidics chips.

The schematic of the portable setup for the measurement of absorbance of the localized surface plasmon resonance (LSPR) band is shown in Figure 1(a). The setup consists of a UV-visible source coupled to a spectrometer through 2 lens collimators attached on 2 metal slots. The metal slots are designed such that the microfluidic chips can be inserted and self-aligned 


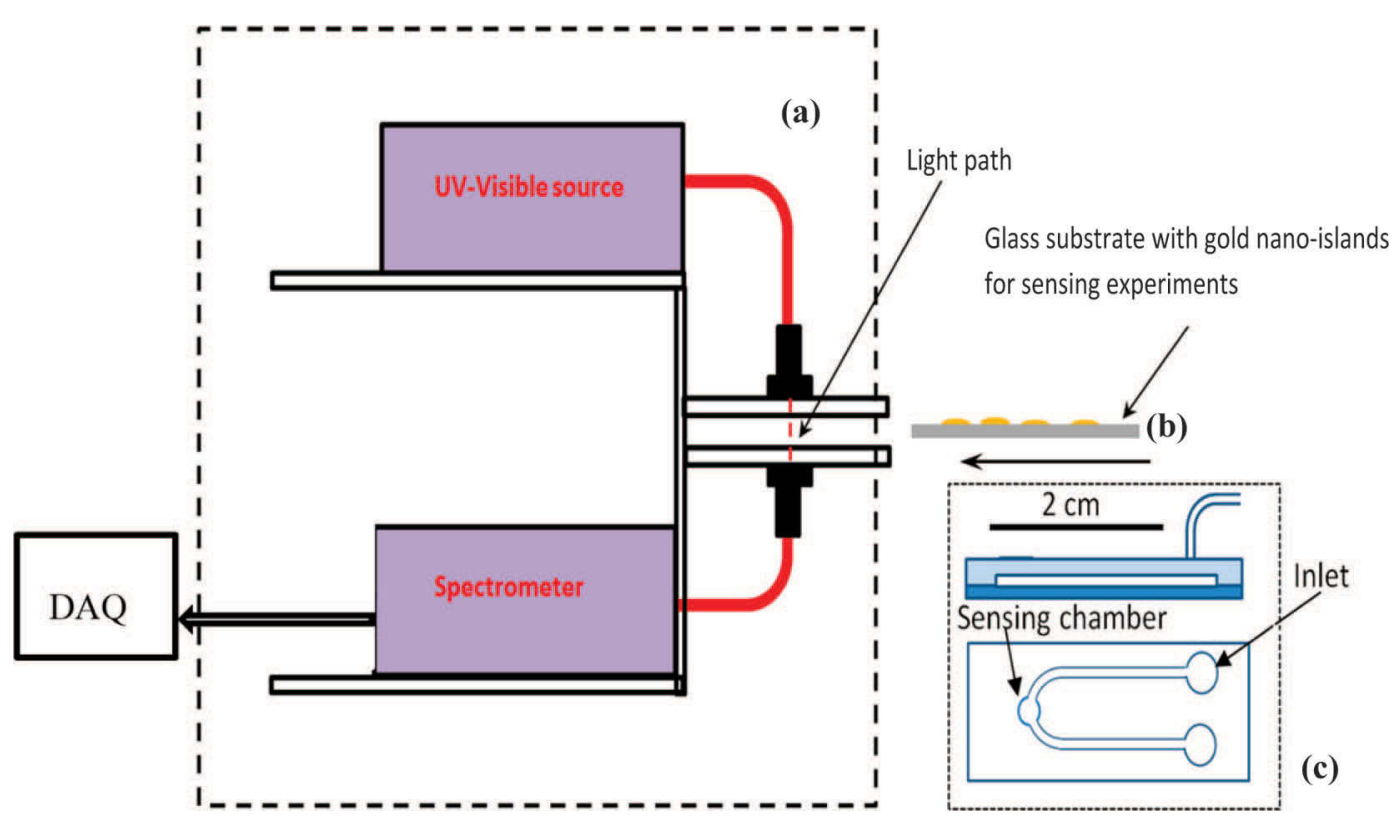

Figure 1. (a) Schematic of the portable device (DAQ = data acquisition laptop), (b) glass substrate with gold nanoislands used for the plasmonic sensing of recombinant protein hormone in milk, and (c) schematic of the microfluidic chips used for the measurements of absorbance of recombinant protein hormone. Color version available online.

in the optical path. Glass substrates with gold nanoislands are used for the plasmonic detection experiments. As shown in Figure 1(b), the substrate with gold nanoislands is inserted into the metal slot and optical measurements are taken. The microfluidic chip is designed and fabricated for absorbance measurements. Figure 1(c) shows the schematic of the microfluidic chip used in the device. The size of the microfluidic chip was $3 \times 1.5 \mathrm{~cm}$.

Gold nanoparticles are extensively used for labelfree detection of proteins due to their strong optical absorbance properties in the UV and visible regions of the electromagnetic spectrum (Heutmekers et al., 2007; Hoa et al., 2007; Willets and Van Duyne, 2007; Huang et al., 2009). The plasmon band, also called LSPR, is due to the collective oscillation of electrons at certain frequencies. The LSPR is sensitive to changes in the refractive index of the surrounding environment; hence, they are useful in immunoassays. The gold nanoislands were formed on the glass substrates by convective assembly and used for detection of hormone separated from the milk using SPE. The SPE process essentially removes the proteins such as casein from milk and leaves a mixture of other proteins and hormone. A known amount of hormone (recombinant bST) was added to skim milk for the detection experiments. The SPE experiments were repeated for milk with various amounts of hormone. Then, the concentration of hormone in the milk and the shift of the LSPR property of the gold nanoislands were investigated. To ensure that the other proteins in the separated mixture were not adsorbed to the gold nanoislands, the gold nanoislands were functionalized with antibodies before the detection process.

\section{Materials}

Acetonitrile, trifluoroacetic acid (TFA), PBS, $N, N^{\prime}$-diisopropylcarbodiimide $N$-hydroxysuccinimide, and the SPE C4 cartridge $(500 \mathrm{mg} / 6 \mathrm{~mL})$ were purchased from Sigma-Aldrich Canada (Oakville, Ontario, Canada). Hydrogen tetrachloroaurate (III) trihydrate $\left(\mathrm{HAuCl}_{4} \cdot 3 \mathrm{H}_{2} \mathrm{O}\right)$ was purchased from Alfa Aesar (Ward Hill, MA). Recombinant bovine somatotropin (rbST) and the corresponding anti-bST were received from Cedarlane (Burlington, ON, Canada).

\section{SPE}

Skim milk samples were spiked with known amounts of rbST. For extraction, an SPE C-4 column was used. Figure 2 illustrates the graphical representation of the SPE processes involved in the separation. The first step in the SPE process is the conditioning of the column. The SPE C-4 column was conditioned with $10 \mathrm{~mL}$ of methanol and $10 \mathrm{~mL}$ of water. Then, the mixture of rbST and milk was added to the column. The washing of the column is a step-wise process; first, it is washed with $5 \mathrm{~mL}$ of water with $0.1 \%$ TFA followed by a mixture of $5 \mathrm{~mL}$ of water:acetonitrile $(70: 30, \mathrm{vol} / \mathrm{vol})$ with 

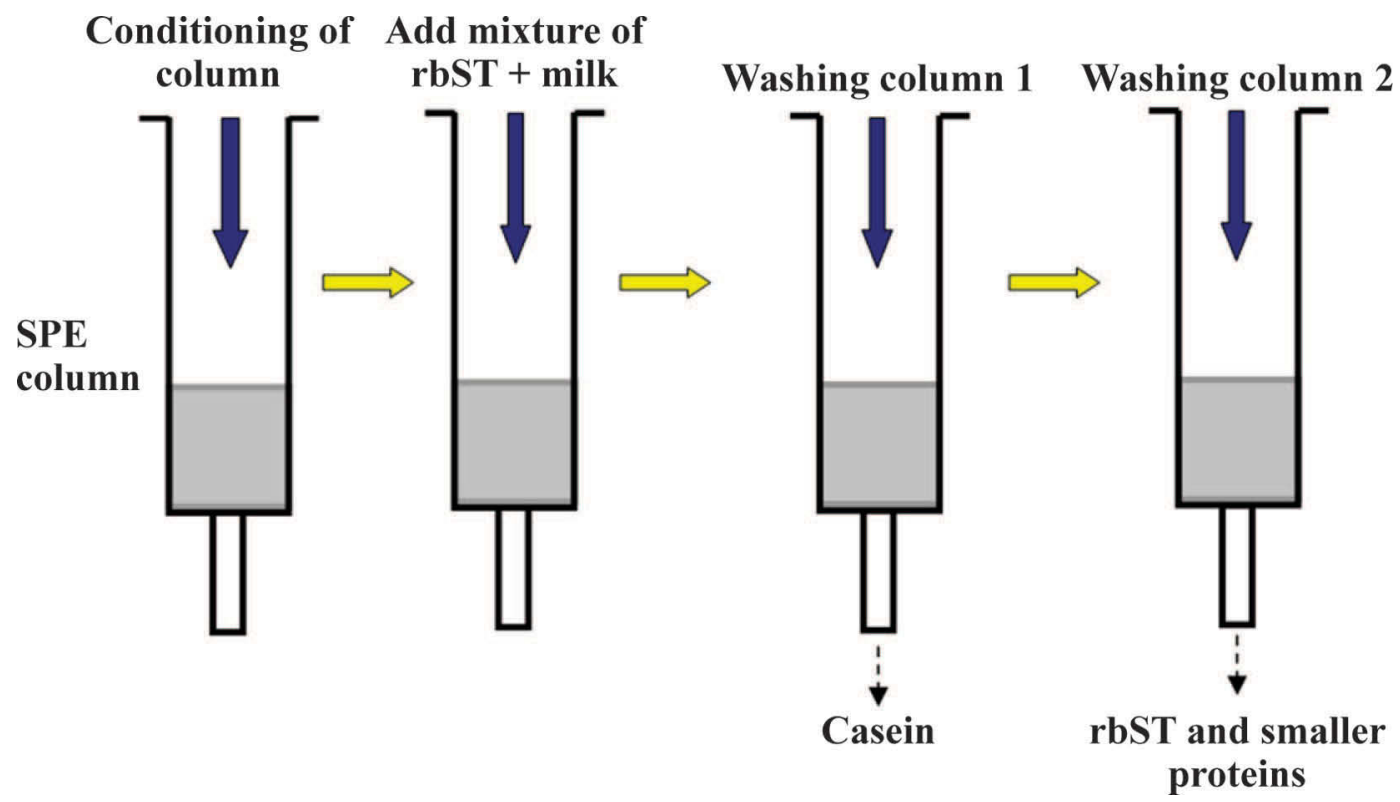

Figure 2. Steps in the solid-phase extraction (SPE) of recombinant bST (rbST) from milk. Color version available online.

$0.1 \%$ TFA. During this process, casein is washed from the column. The next step is collection of a sample containing a mixture of proteins in the milk. The column was eluted with $7 \mathrm{~mL}$ of water:acetonitrile mixture (20:80, vol/vol) containing $0.1 \%$ TFA. The absorbance spectrum of the sample containing various amounts of rbST was measured by using a polydimethylsiloxane (PDMS; manufactured by authors) microfluidics chip.

\section{Fabrication of the PDMS Microfluidics Chip}

The microfluidic chip used for the absorbance measurement of rbST has a fluidic chamber along a Ushaped microfluidic channel. The chip was designed so that it could be inserted into the portable optical device such that the fluidic chamber was self-aligned in the light path. The device was fabricated using soft lithography and oxygen plasma bonding. The mold for the soft lithography was fabricated using SU-8 lithography. Then, a PDMS microfluidic chip was fabricated using Sylgard 184 elastomer kit (Dow Corning, Midland, MI) as described previously (Ozhikandathil and Packirisamy, 2012a). The PDMS chip and glass substrates were bonded using oxygen plasma bonding and the fluidic tubes connected. Figure 3(a) shows the 3 -dimensional model of the microfluidic chip. The chip has 2 microreservoirs at the inlet and outlet of the chips and a sensing chamber as shown in Figure 3(a). The sensing chamber is aligned to the optical path when the chip is inserted to the portable device. Figure $3(\mathrm{~b})$ shows a photograph of the fabricated microfluidic chips used for the absorbance measurements.

\section{Portable Testing Setup}

The portable device for the detection of growth hormone is packaged in a box of $20 \times 15 \times 15 \mathrm{~cm}$, as shown in Figure 4. The device includes a pulsed xenon light source (PX2, Ocean Optics, Winter Park, FL), a spectrometer (USB5000, Ocean Optics), 2 fiber collimators, and a metal rack to accommodate the microfluidic chip along the light path. The metal rack was designed and integrated with the device to self-align the fluidic chamber with the light path. The UV-visible light $(200-800 \mathrm{~nm})$ is coupled to the microfluidic chip and then to the spectrometer using 2 multimode fibers through the fiber collimators. The spectrum was recorded using data acquisition software (Spectra suite, Ocean Optics). For each absorbance measurement, 2 identical chips were used, one for the baseline measurements, without the sample and suspension medium only, and the other one with the samples.

\section{Fabrication of Gold Nanoislands}

The detailed modeling and process of fabrication of gold nanoislands were reported previously (Ozhikandathil et al., 2012b). The process is simple and can be carried out in any general laboratory environment. First, the gold colloidal solution is prepared by conventional 

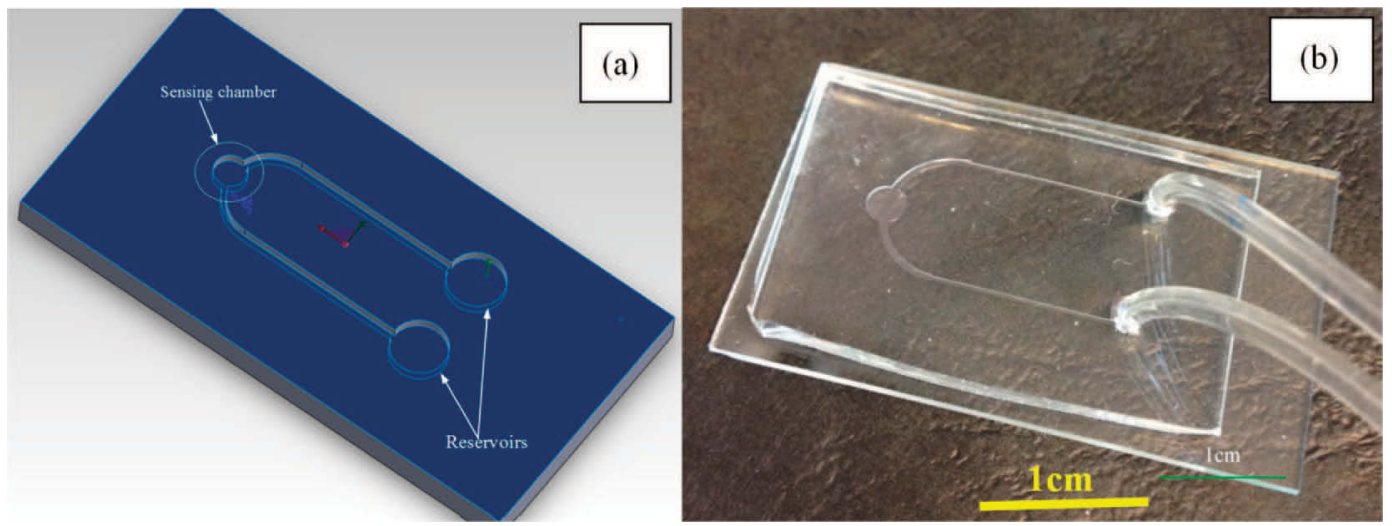

Figure 3. (a) 3-Dimensional model of microfluidic chip, and (b) photograph of the microfluidics chip. Color version available online.

Turkevich's method. The nanoparticles were deposited on a glass substrate by convective assembly and postdeposition annealing was carried out. To deposit the nanoparticles, the glass samples were cleaned in soap solution, deionized water, acetone, and 2-propanol. The substrates were baked at $100^{\circ} \mathrm{C}$ for $1 \mathrm{~h}$ before deposition. Then, the glass substrate was silanized to promote adsorption of nanoparticles to the glass substrate. Finally, the substrates were kept in the gold colloidal solution at an angle $\left(\sim 30^{\circ}\right)$ and then kept in an oven at $80^{\circ} \mathrm{C}$ for $24 \mathrm{~h}$. The deposited film had a nanocluster morphology, with a wide optical absorbance spectrum.

The initial adhesion of nanoclusters to the glass substrate was not strong. The samples were annealed at $600^{\circ} \mathrm{C}$ to yield widely separated nanoislands with a narrow LSPR spectrum. The high temperature annealing at $600^{\circ} \mathrm{C}$ for $18 \mathrm{~h}$ resulted in a nanoisland morphology with strong adhesion to the substrate. The nanoislands have a pink color as shown in Figure 5(a). The morphological and optical characterizations of the nanoislands were carried out using scanning electron microscopy and UV-visible spectroscopy, respectively, as shown in Figure 5(b), (c), and (d). The morphology of the film showed well-separated nanoislands with a wide size distribution as shown in Figure 5(d). The size distribution of the nanoislands was characterized using the Gwyddion free software (http://gwyddion.net/ download.php). The gold nanoislands had a size distribution between 10 and $120 \mathrm{~nm}$, and most of the islands were in the $70 \pm 10 \mathrm{~nm}$ range. The size characterization was carried out for 10 samples at various locations in the scanning electron microscope image, and the average measurements were plotted in the histogram shown in Figure 5(d).

The absorbance of the nanoislands was measured using the developed portable device. We observed that samples before annealing had nanocluster morphology, and the optical absorbance band was wide, extending from 450 to $750 \mathrm{~nm}$, as shown in our previous work. Bio-sensing experiments using nanoclusters were also carried out in our previous work (Ozhikandathil et al., 2010). The wide band was not suitable for bio-sensing because the peak of the band was not precisely defined and hence the measurement of the shift of the peak was

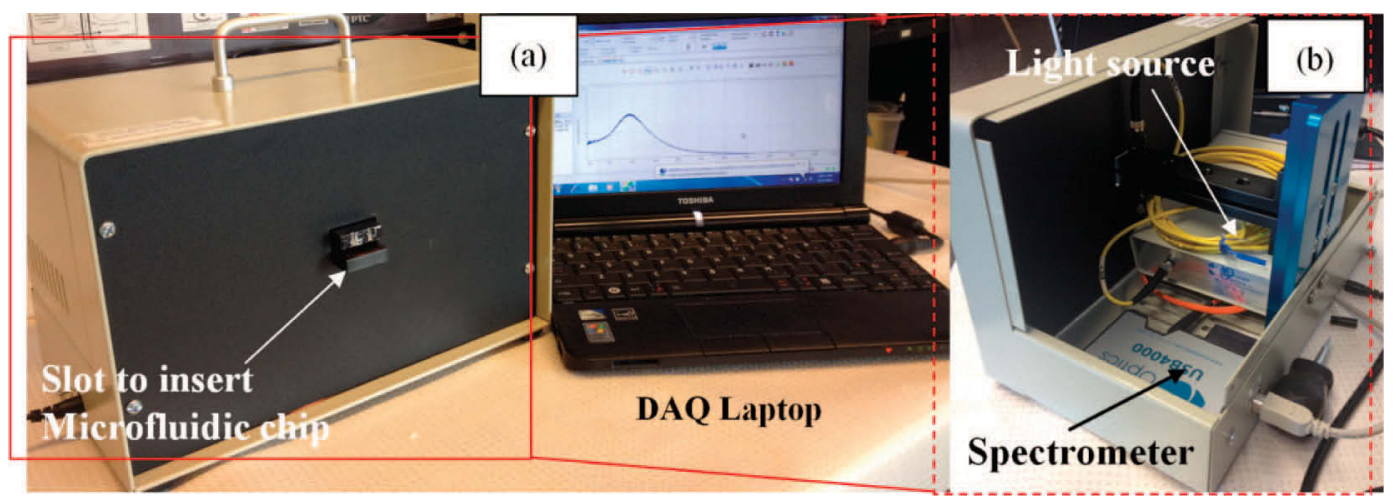

Figure 4. Portable device and data acquisition (DAQ) laptop: (a) The device connected to the laptop, and (b) the internal setup for incorporating microfluidic chip. Color version available online. 


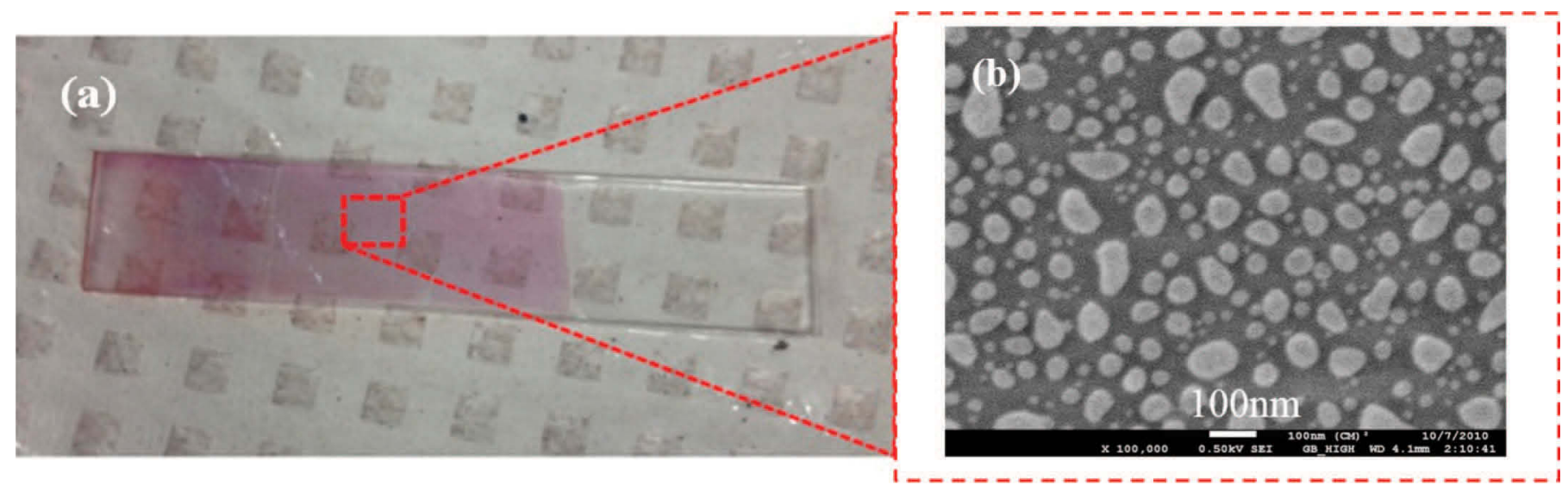

(c)

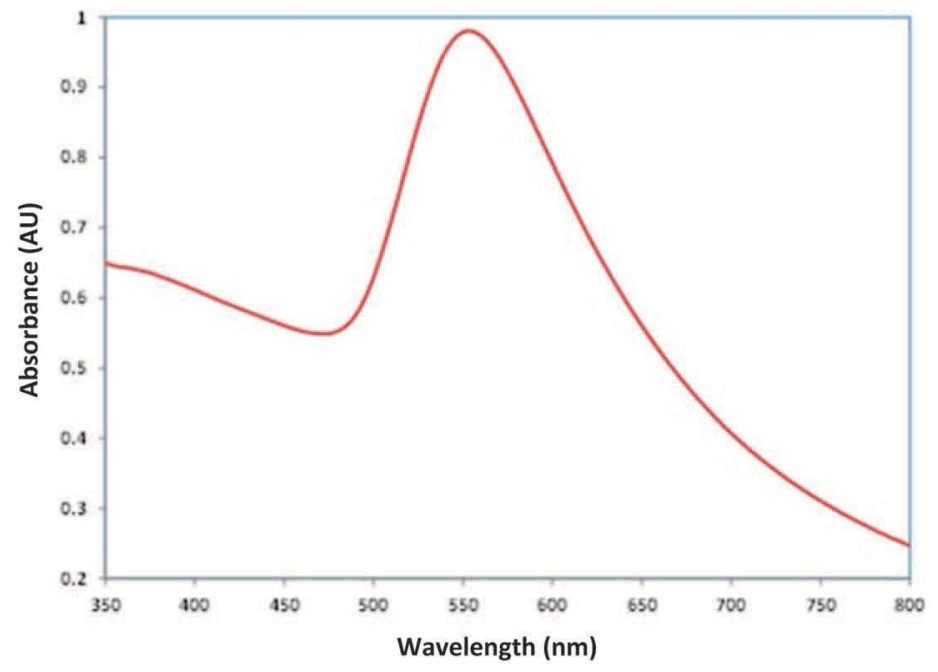

(d)

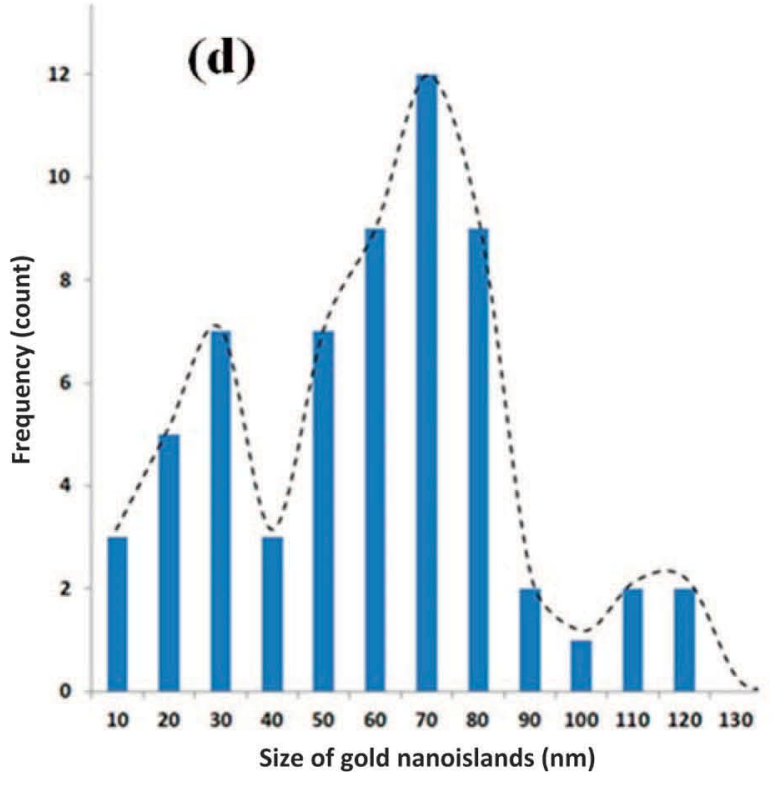

Figure 5. (a) Glass substrate with gold nanoislands, (b) scanning electron micrograph of gold nanoislands, (c) localized surface plasmon resonance (LSPR) spectrum of gold nanoislands, and (d) size distribution of nanoislands. Color version available online.

difficult. The annealing of nanoclusters resulted in a widely separated nanoisland morphology, with a clearly defined absorbance peak at $545 \pm 5 \mathrm{~nm}$. Figure 5(c) shows the LSPR spectrum of the nanoisland morphology. The UV-visible characterization was carried out on 120 samples, and the results confirmed the repeatability of the measurements.

\section{Optical Absorbance Measurement of Hormone Separated from Milk Using the Portable Device}

The SPE of rbST from the milk samples spiked with known amounts of rbST was carried out as explained in the SPE section. The elution samples obtained in the second column-washing step contained a mixture of proteins and rbST. To confirm that the elution mixture contained rbST, optical spectroscopy measurement was carried out using the microfluidic chip. The milk samples were spiked with various rbST concentrations in the range from 5 to $25 \mathrm{ng} / \mathrm{mL}$. Figure 6 shows the absorbance spectrum of the elution mixture containing $\mathrm{rbST}$ and other proteins extracted from the milk samples. The spectrum had an absorbance peak at 280 $\mathrm{nm}$, representing the optical absorbance of $\mathrm{rbST}$ and other proteins in the milk. The SPE and optical absorbance measurements were repeated for milk samples spiked with various concentrations of rbST. A small absorbance peak was observed for samples without rbST (0 ng/mL), which represents the absorbance of other proteins in the milk samples. A linear trend in optical absorbance against concentration can be seen in Figure $6(\mathrm{a})$ and (b). Then, the samples were used for specific detection of rbST using the gold nanoislands with antibST. The SPE and optical absorbance measurements 

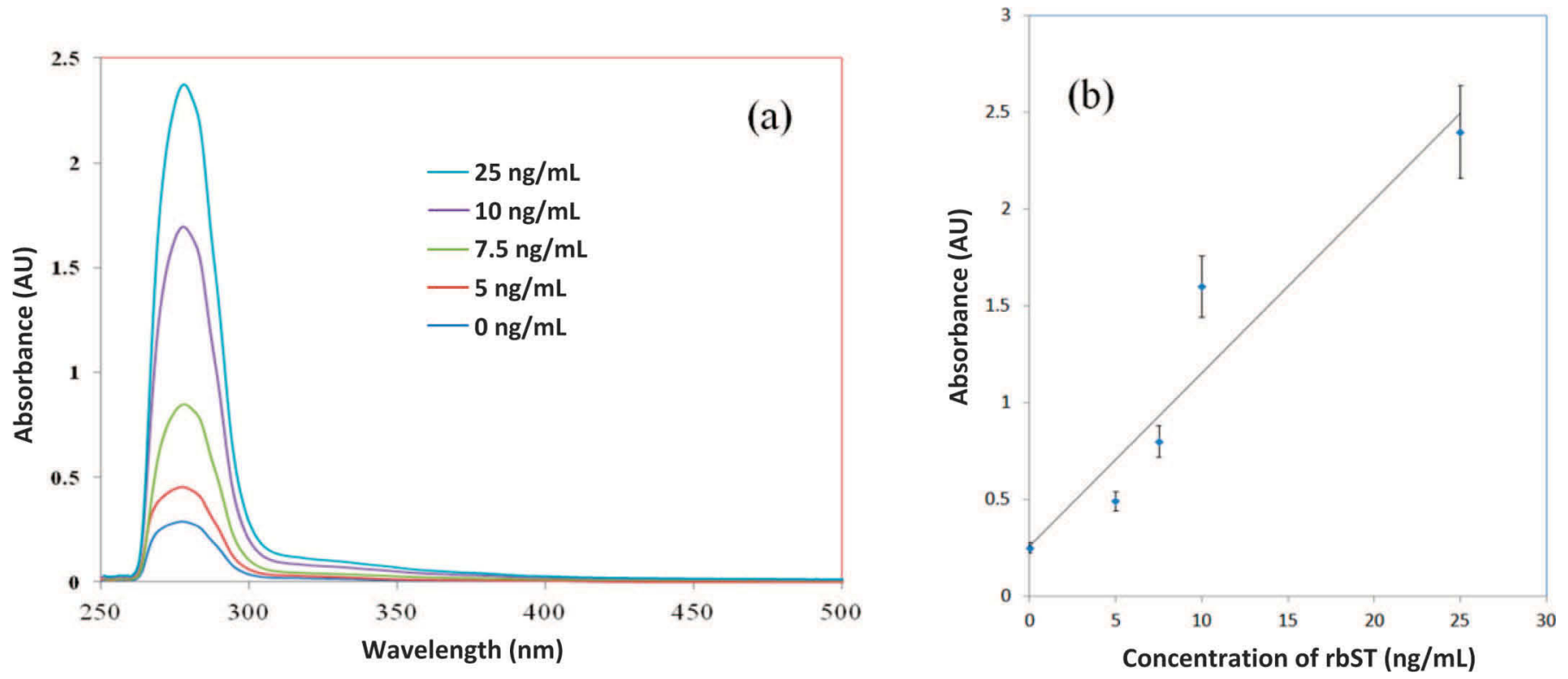

Figure 6. (a) A typical UV-visible absorbance spectrum recorded for the solid-phase extraction samples, and (b) recombinant bST (rbST) absorbance calibration (in arbitrary units). Error bar represents the standard deviation of 10 measurements. Color version available online.

were carried out on 10 samples for each concentration. The error bar in Figure 6(b) represents the standard deviation of 10 measurements.

\section{Detection of Hormone Using Gold Nanoislands}

As most of the proteins had an absorbance peak at $280 \mathrm{~nm}$, it was impossible to detect a specific protein from a complex mixture by measuring only the absorbance spectrum. To add specificity to the detection, anti-bST was required to functionalize the gold nanoislands, which ensures that only bST is adsorbed to the nanoislands for plasmonic detection. The immunoassay protocol for the specific adsorption of bST on the gold nanoislands is demonstrated in Figure 7. Various chemical processes involved in the detection are described in Figure 7. Step 1 shows the gold nanoislands deposited on the glass substrate. First, the samples were soaked in the solution of the linker (mercaptoundecanoic acid in ethanol) for $1 \mathrm{~h}$; then, the sample was washed with ethanol. Step 2 in Figure 7 shows the sample with the linker molecule. Then, the cross-linker (i.e., $N, N$ diisopropylcarbodiimide $N$-hydroxysuccinimide) was added to the samples and washed in PBS. The linker helps adsorb the cross-linker and anti-bST on the gold nanoislands. Step 3 in Figure 7 indicates the sample with the adsorbed cross-linker. The anti-bST solution $(100 \mathrm{ng} / \mathrm{mL}$ ) was added to the sample and kept for at least $1 \mathrm{~h}$ to be adsorbed on the gold nanoislands. The sample with anti-bST is represented in step 4 of Figure 7. The next step is blocking the surface of nanoislands where no anti-bST is adsorbed, which is required to minimize the error in detection due to nonspecific adsorption. We have tested both BSA and nonfat milk powder solution as blockers and confirmed that both act as good blockers for hormone detection experiments in milk. The sample with blocker and anti-bST is shown in step 5 of Figure 7. Finally, rbST solutions of various concentrations were added to the samples to adsorb to the gold nanoislands through antigen-antibody interaction. The samples were washed in PBS in each steps. For plasmonic detection experiments, the LSPR spectrum of the sample was recorded in steps 5 and 6 in order to assess the shift of LSPR peak to evaluate the antigen-antibody interaction.

Figure 8(a) shows the change in the LSPR spectrum during the sensing experiment. The 3 curves represent the LSPR spectra recorded at various steps in the assay. Curve (1) represents the LSPR spectrum corresponding to the gold nanoislands recorded before starting the experiment. As explained in the Fabrication of Gold Nanoislands section, the nanoislands had an absorbance peak at $545 \mathrm{~nm}$. The peak of the spectrum was shifted to $550 \mathrm{~nm}$ with the adsorption of anti-bST and blocker molecules as shown in curve (2), which is measured in step 5 of the immunoassay. In the final step, the rbST and protein mixture separated by the SPE process was adsorbed to the sample and the measurement was taken. Spectrum (3) of Figure 8(a) corresponds to the change of LSPR spectrum after the antibody-antigen interaction with rbST at a concentration of $25 \mathrm{ng} / \mathrm{mL}$. The LSPR peak was shifted by 5 

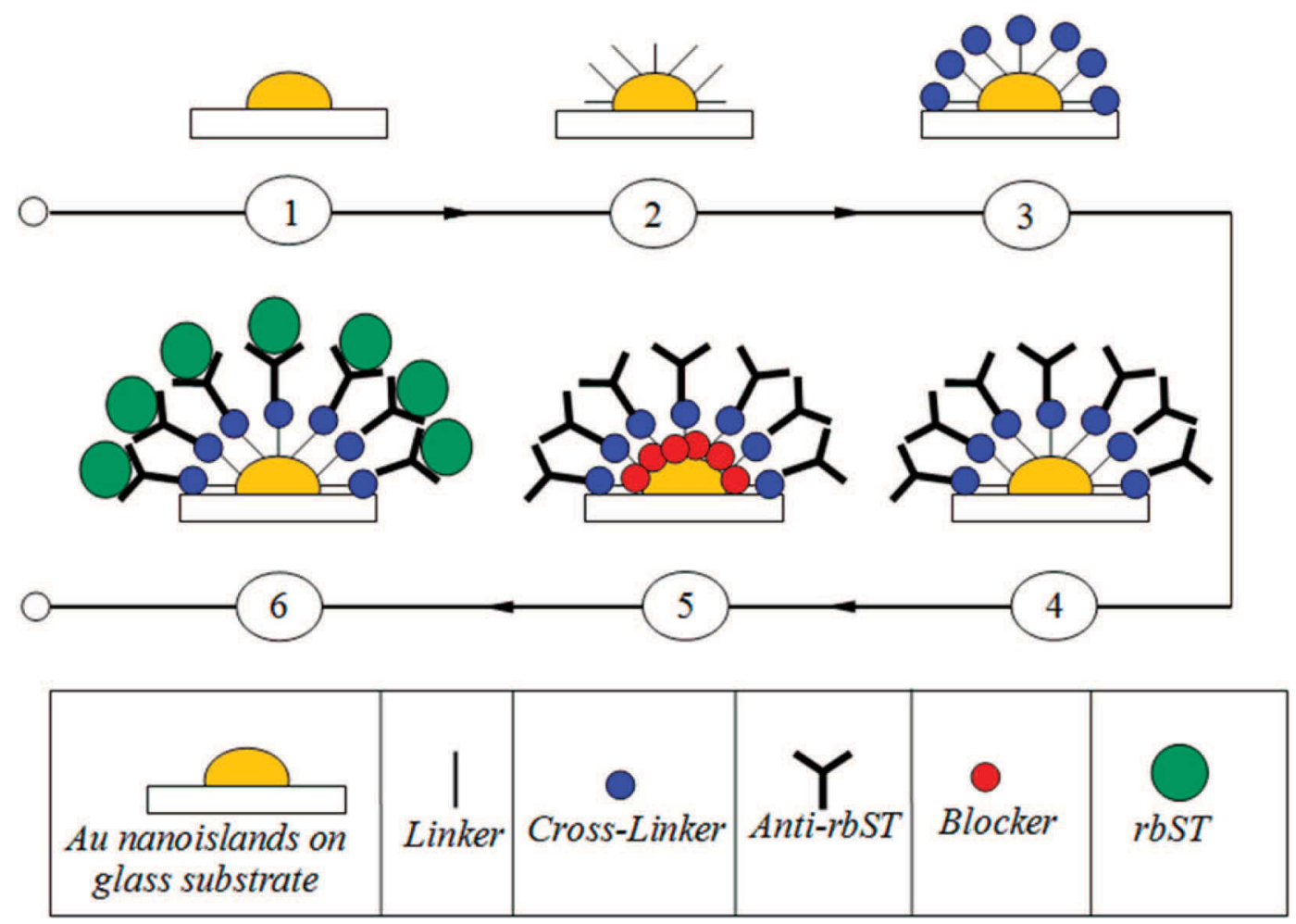

Figure 7. Immunoassay protocol for the detection of recombinant bST (rbST). (1) Sample with gold nanoislands, (2) gold nanoislands with linker, (3) sample after adding cross-linker, (4) sample after adding anti-bST, (5) sample after adding blocker, and (6) sample after adding rbST. Color version available online.

$\mathrm{nm}$ due to the antigen-antibody interaction. To verify the repeatability of the measurement and establish a sensor calibration curve, the experiments were repeated on several samples with various concentrations of rbST ranging between 1 and $25 \mathrm{ng} / \mathrm{mL}$. Figure 8(b) shows the sensor calibration curve. The sensor was able to
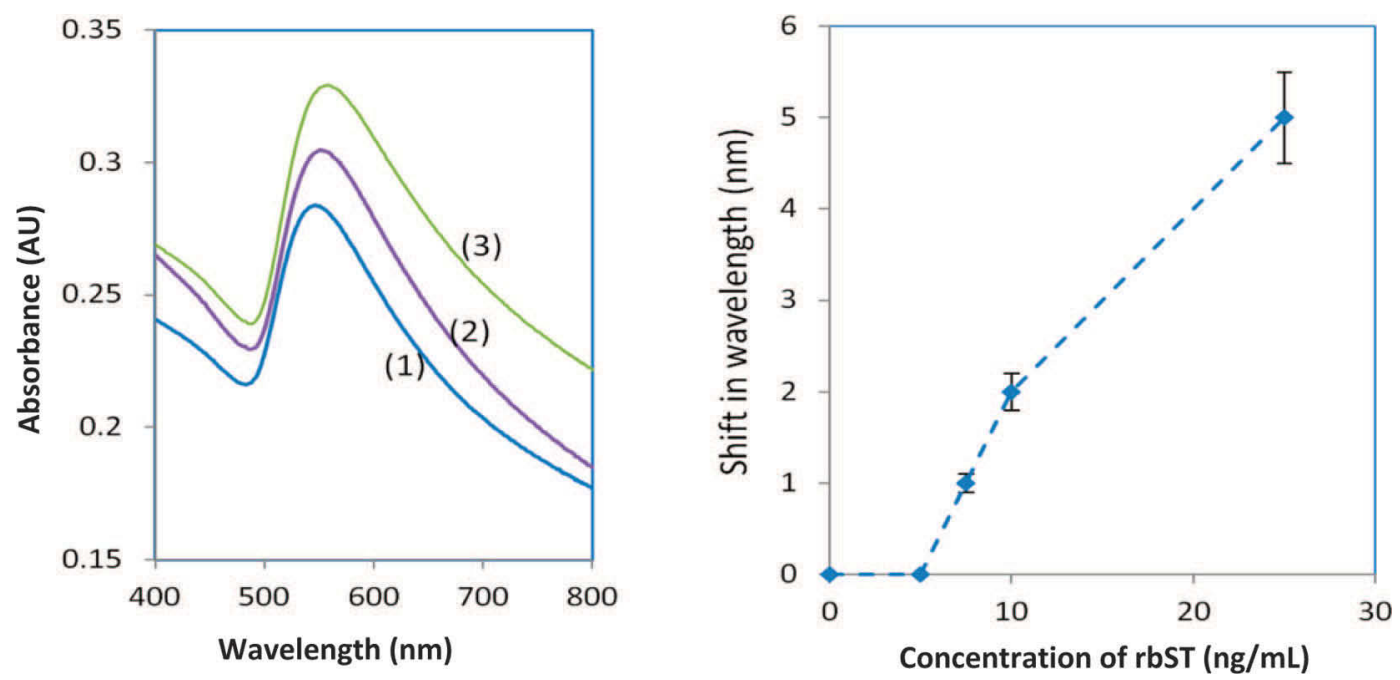

Figure 8. (a) Change in the position and absorbance of the gold nanoisland structure during the various stages of the immunoassay: (1) before starting the immunoassay, (2) after anti-bST was adsorbed to the gold, and (3) after rbST was adsorbed to the gold; (b) sensing experiments carried out for various concentrations of rbST; shift of localized surface plasmon resonance (LSPR) spectrum as a function of concentration of $\operatorname{rbST}(\mathrm{ng} / \mathrm{mL})$. Color version available online. 
detect rbST from the SPE elution mixture at a concentration as low as $5 \mathrm{ng} / \mathrm{mL}$ (the error bar represents the standard deviation of 10 measurements taken on samples of various concentration of rbST).

We describe a portable and low-cost method of detecting protein hormone in milk samples. Milk samples were spiked with various concentrations of rbST, and $\operatorname{rbST}$ was extracted with an SPE technique. The measurement of absorbance of the hormone separated from milk was carried out on a microfluidics chip using a portable device. Furthermore, plasmonic detection of hormone was carried out using gold nanoisland structures deposited on glass by a simple and low-cost convective assembly method. The proposed method of detection of hormone in milk is simple, cheaper, and faster than other techniques. The spiked rbST in milk samples could be detected at levels as low as $5 \mathrm{ng} / \mathrm{mL}$. Regarding the further developments of the device, we intend to integrate the spectrometer and light source within the microfluidic chip. In addition, integration of the sample extraction module into the microfluidic chip would eliminate the need for external sample preparation.

\section{ACKNOWLEDGMENTS}

The authors thank Développement économique, innovation et exportation (MDEIE) Québec for the financial support and Concordia Research Chair of M. Packirisamy for the financial support.

\section{REFERENCES}

Castigliego, L., G. Iannone, G. Grifoni, R. Rosati, D. Gianfaldoni, and A. Guidi. 2007. Natural and recombinant bovine somatotropin: Immunodetection with a sandwich ELISA. J. Dairy Res. 74:79-85.

Hadjipanayiotou, M. 1995. Composition of ewe, goat and cow milk and of colostrum of ewes and goats. Small Rumin. Res. 18:255-262.
Heutmekers, T. H. J., M. G. E. G. Bremer, W. Haasnoot, and M. W. F. Nielen. 2007. A rapid surface plasmon resonance (SPR) biosensor immunoassay for screening of somatotropins in injection preparations. Anal. Chim. Acta 586:239-245.

Hoa, X. D., A. Kirk, and M. Tabrizian. 2007. Towards integrated and sensitive surface plasmon resonance biosensors: A review of recent progress. Biosens. Bioelectron. 23:151-160.

Huang, C., K. Bonroy, G. Reekmans, W. Laureyn, K. Verhaegen, I. De Vlaminck, L. Lagae, and G. Borghs. 2009. Localized surface plasmon resonance biosensor integrated with microfluidic chip. Biomed. Microdevices 11:893-901.

Jindal, S. K., and R. S. Ludri. 1990. Growth hormone concentration in lactating crossbred cows and buffaloes. Asian-australas. J. Anim. Sci. 3:319-322.

Le Breton, M. H., A. Beck-Henzelin, J. Richoz-Payot, S. RochereauRoulet, G. Pinel, T. Delatour, and B. Le Bizec. 2010. Detection of recombinant bovine somatotropin in milk and effect of industrial processes on its stability. Anal. Chim. Acta 672:45-49.

Ozhikandathil, J., S. Badilescu, and M. Packirisamy. 2010. Synthesis and optical properties of immobilized spherical and non-spherical gold nanoparticles for detection of polypeptides and microfluidics applications. Paper no. 591 in Int. Conf. Nanotechnology: Fundamentals and Applications, Ottawa, Canada.

Ozhikandathil, J., S. Badilescu, and M. Packirisamy. 2012a. Detection of fluorophore-tagged recombinant bovine somatotropin (rbST) by using a silica-on-silicon (SOS)-PDMS lab-on-a-chip. IEEE Sens. J. 12:2791-2798.

Ozhikandathil, J., S. Badilescu, and M. Packirisamy. 2012b. Gold nanoisland structures integrated in a lab-on-a-chip for plasmonic detection of bovine growth hormone. J. Biomed. Opt. 17:077001.

Ozhikandathil, J., and M. Packirisamy. 2012a. Silica-on-silicon waveguide integrated polydimethylsiloxane lab-on-a-chip for quantum dot fluorescence bio-detection. J. Biomed. Opt. 17:017006.

Ozhikandathil, J., and M. Packirisamy. 2012b. Nano-islands integrated evanescence-based lab-on-a-chip on silica-on-silicon and polydimethylsiloxane hybrid platform for detection of recombinant growth hormone. Biomicrofluidics 6:46501.

Ozhikandathil, J., and M. Packirisamy. 2013. Detection of recombinant growth hormone by evanescent cascaded waveguide coupler on silica-on-silicon. J. Biophotonics 6:457-467.

Rochut, N., B. Le Bizec, F. Monteau, and F. André. 2000. ESI-MS for the measurement of bovine and porcine somatotropins: Mass spectrometry for the study of natural mechanisms. Analusis $28: 280-284$.

Willets, K. A., and R. P. Van Duyne. 2007. Localized surface plasmon resonance spectroscopy and sensing. Annu. Rev. Phys. Chem. $58: 267-297$. 